\title{
Potencialidades del archivo público de narrativas digitales "Humanizando la Deportación" como fuente histórica para el estudio de las migraciones internacionales
}

\section{Potentialities of the public archive of Digital Storytelling "Humanizing Deportation" as a historical source for the study of international migration}

\author{
Ana Luisa Calvillo Vázquez* \\ Guillermo Hernández Orozco***
}

\begin{abstract}
*Estudiante del Doctorado en Educación, Artes y Humanidades de la Universidad Autónoma de Chihuahua (México). Es maestra en Humanidades por la Universidad Autónoma de Chihuahua. Entre sus publicaciones se encuentran los libros 60 años del deporte universitario de la UACH y Me decian mexicano frijolero (Premio Nacional de Testimonio Carlos Montemayor 2013). "El desalojo de los residentes de El Bordo en Tijuana: una profilaxis social contra las poblaciones precarizadas", en proceso de publicación por El Colegio de la Frontera Norte, Tijuana. Entre sus temas de interés están la historia e historiografía de la educación y los estudios migratorios.Correo electrónico ana.calvillo.vazquez@gmail.com
\end{abstract}

(D) https://orcid.org/0000-0001-9382-0398

**Profesor de la Universidad Autónoma de Chihuahua (México). Es doctor en Ciencias de la Educación por el Instituto Superior Pedagógico Enrique José E. Varona (Cuba). Entre sus publicaciones recientes están: "José Joaquín Calvo López, fundador del Instituto Científico y Literario, hoy Universidad Autónoma de Chihuahua" en IE Revista de Investigación Educativa, Vol. 8, No. 14 (2017); Debates por la Historia (Cinco tomos). Reconocimiento Eduardo Flores Kastanis a la Investigación Educativa 2018; Perfil Prodep y reconocimiento del Sistema Nacional de Investigadores Nivel 1. Su tema de interés es la historia e historiografia de la educación. Correo electrónico ghernand@uach.mx

(D) https://orcid.org/0000-0001-7287-8240

Historial editorial

Recibido: 10-mayo-2018

Primera revisión: 13-mayo-2018

Segunda revisión: 06-agosto-2018

Aceptado: 19-agosto-2018

Publicado: 31-octubre-2018 
Potencialidades del archivo público de narrativas digitales "Humanizando la Deportación" como fuente histórica para el estudio de las migraciones internacionales

\section{Resumen}

En este trabajo se revisa la potencialidad del archivo público de narrativas digitales "Humanizando la Deportación", de la Universidad de California, Davis, como fuente histórica para el estudio de las migraciones internacionales y otras aproximaciones epistemológicas, porque rescata y preserva la voz de las personas afectadas por la deportación, pero desde la perspectiva de la autorepresentación de los narradores comunitarios, lo cual representa su principal aportación al campo de los estudios migratorios. Además de tratarse de una propuesta innovadora, el archivo constituye un valioso recurso historiográfico que ofrece información sobre las consecuencias humanas de la deportación, más allá de las estadísticas, los discursos oficiales y otros productos mediáticos que han documentado este fenómeno.

Palabras Clave: Migraciones internacionales, deportación, narrativa digital, historia oral, memoria colectiva e histórica. 
Potentialities of the public archive of Digital Storytelling "Humanizing Deportation" as a historical source for the study of international migration

\begin{abstract}
This paper seeks to explore the possible potential as a historical source for the study of international migrations and other epistemological approaches of the "Humanizing Deportation" Digital Storytelling public archive, from the University of California, Davis. This archive gathers and revives the voice of people affected by deportation from the point of view of the self-representation of community narrators, being therefore its main contribution to the field of migration studies. This archive represents both an innovative proposal and a valuable historiographical source as it provides information regarding the human consequences of deportation that go beyond statistics, official political discourse and other media products that have documented this phenomenon.
\end{abstract}

Keywords: International migrations, deportation, digital storytelling, oral history, collective and historical memory. 


\section{Introducción}

El archivo público de narrativas digitales "Humanizando la Deportación" fue publicado en 2017 a raíz de un proyecto coordinado por el profesor Robert McKee Irwin, director del posgrado en Estudios Culturales y co-director de la Iniciativa Mellon en Estudios Comparados de la Frontera, de la Universidad de California, Davis, ${ }^{\mathrm{I}}$ con el propósito de ofrecer información testimonial sobre la crisis humanitaria que se estaba viviendo en nuestro país como consecuencia de las deportaciones masivas de mexicanos de Estados Unidos, más allá de lo que expresaban las estadísticas, los discursos oficiales e incluso otros productos mediáticos de corte periodístico que han documentado el fenómeno, y para contrarrestar la visión estereotipada que se tenía sobre esta población, según explica la página oficial del proyecto. $^{2}$

El trabajo se concibió como un tipo de activismo para informar sobre las consecuencias humanas de la deportación, en un esfuerzo conjunto entre instituciones universitarias como El Colegio de la Frontera Norte, Tijuana, y la UC Davis (McKee, 20I6). Para ello, implementaron el método de la narrativa digital con personas retornadas de Estados Unidos que residían en la ciudad de Tijuana, Baja California.

Desde los años sesenta, Tijuana ha sido el principal enclave de cruce fronterizo tanto a nivel nacional como latinoamericano, y desde los años noventa el estado de Baja California es la entidad que ha recibido a más personas retornadas de Estados Unidos. Según datos de la SEGOB (20I5), de I995 a 20I6, Baja California tuvo 5.5 millones de eventos de repatriación, de los cuales el 70\% ingresó por Tijuana, mientras que en otras entidades como Sonora se presentaron 3.8 millones de repatriaciones; en Tamaulipas, I.8 millones; en Chihuahua I.2 millones, y en Coahuila, la Ciudad de México y Jalisco, 
menos de un millón de eventos de repatriación en el mismo periodo (se categorizan como tales porque una persona pudo haber sido retornada varias veces). Por esta razón, Tijuana puede considerarse el epicentro de la crisis migratoria en México.

La narrativa digital, como método que abrevó del paradigma sociocrítico, estimula el empoderamiento de los narradores comunitarios para que alcancen un nivel de agencia, al facilitar un proceso de autorepresentación, mediante el cual las personas expresan su problemática desde su propia subjetividad, experiencia y creatividad, ya que son ellas mismas quienes deciden lo que quieren contar y la forma de hacerlo. Esta agencia es la recuperación de la posibilidad de movilización, actuación e intervención en la vida social, como señalan Arcudia y Pérez (2014), pues el individuo hace uso de las alternativas que se le presentan y opta por aquella con la que puede transformar el contexto social mediante sus acciones.

Una vez que el proyecto "Humanizando la Deportación" desarrolló este proceso, publicó las narrativas digitales en el sitio oficial del proyecto con la autorización expresa de los narradores comunitarios para ponerlo a disposición tanto de la audiencia como de los investigadores de cualquier parte del mundo, a fin de que el contenido del archivo fuese pensado y problematizado desde la academia. $^{3}$

Hasta el mes de septiembre de 2017 , el archivo reunía 45 narrativas digitales de los participantes de Tijuana. Sin embargo, el proyecto se ha ido replicando en otros estados de la República como Guadalajara, la Ciudad de México, Oaxaca y Ciudad Juárez, con la participación del Instituto Tecnológico y de Estudios Superiores de Monterrey, la Universidad de Guadalajara y la Universidad Autónoma de 
Chihuahua (Ciudad Juárez), por lo que el archivo continúa en expansión.

Es así como en este caso se revisa su potencialidad como fuente histórica para el estudio de las migraciones internacionales, y concretamente para el estudio de las deportaciones masivas. Para lograr este objetivo, se explican los fundamentos del método de la narrativa digital, el contenido del archivo público de narrativas digitales "Humanizando la Deportación", y sus posibles aplicaciones desde la perspectiva historiográfica.

\section{El método de la narrativa digital}

La narrativa digital tiene sus raíces en el movimiento por el arte popular desarrollado en Estados Unidos, en los años setenta y ochenta, que buscaba descentralizar el arte de las élites e impulsar la producción artística alternativa mediante la expresión de historias personales que no habían sido visibilizadas, debido a conflictos sociales y políticos (Lambert, 2013).

A partir de la diversificación y popularización de las tecnologías digitales en los años noventa, surgieron nuevas formas de expresión y experimentación, así que un grupo de artistas se unieron para explorar cómo estas herramientas podían potencializar las narrativas personales, y fundaron el Centro de Medios Digitales de San

90 Francisco (San Francisco Digital Media Center), que después sería el Centro de Narrativas Digitales (Center for Digital Storytelling) y finalmente, el StoryCenter, que desde 2015 ha trabajado con casi mil organizaciones alrededor del mundo en la implementación de este método. 
La narrativa digital es un género testimonial en formato digital que se relaciona con otros productos culturales mediáticos que también se denominan narrativas digitales - juegos de video, hipertextos-, pero como método que abrevó del paradigma sociocrítico tiene su propia especificidad, pues se trata de un conjunto de técnicas colaborativas para la participación social (Spurgeon, 2009).

Uno de sus fundamentos es restaurar la autoría de las personas, es decir, su autoridad para hablar sobre aquello que no se conoce o se da por sentado en la esfera pública, dado que "la voz no está distribuida democráticamente” (Lambert, 20I3, p. 4I). La autoría crea agencia porque propicia acción y transformación. Esta autoexpresión permite que la persona se apropie de su existencia, de sus emociones y de la experiencia vivida, en una reelaboración del pasado que le descubre asideros para seguir adelante, con lo cual reafirma su identidad y encuentra un nuevo equilibrio.

De acuerdo con Lambert (2013), lo opuesto a la autoría es el autoritarismo, que jerarquiza, estratifica y por último margina y silencia desde una posición de privilegio. El actuar con autoritarismo implica que quien ostenta el poder de la expresión decide lo que las personas pueden decir o construye estereotipos acerca de su historia. En cambio, este método invierte las jerarquías tradicionales al adoptar una postura solidaria que deposita el control del proceso en la persona. Como afirma McKee (20I6), justamente cuando se asume que los participantes no son informantes, sino miembros del equipo, se desarman las posiciones de poder.

La narrativa digital apela a la capacidad innata de los seres humanos para contar una historia. No se trata de documentales, ni de entrevistas grabadas; son historias breves, de dos a cinco minutos, contadas e ilustradas por las personas mismas, por lo que su 
producción es de tipo artesanal. Lo que se busca es desarrollar un proceso, más que un producto (Mak, 20I2).

Por otra parte, las narrativas digitales no aspiran a la distribución masiva, aunque puede darse a través de internet, partiendo de que se ha producido una reconfiguración de los medios de comunicación que ha expandido las formas de expresión ciudadana; es decir, se han ampliado las oportunidades de representación directa en lugar de indirecta (Spurgeon, 2009). Dicho de otra forma, se ha dado acceso a la creación y a la difusión, lo cual provee de mayor agencia al productor del mensaje.

Burgess (2006) considera que a raíz de la proliferación de los medios digitales se dio una ruptura en los medios de comunicación dominantes que cambió el paradigma de la audiencia pasiva por el de la audiencia activa. De acuerdo con la autora, este nuevo esquema se basa en la creatividad vernácula: prácticas creativas que están fuera de las élites y de las convenciones comunicacionales, lo cual significa una inversión de lo nativo contra lo oficial; la cotidianidad contra la institucionalidad, y, en suma, el discurso individual versus el discurso hegemónico.

De esta manera, la narrativa digital como un género de narración democratizadora (Lizarazo, Oceguera, Tenorio, Pardo y McKee, 20I7), constituye una forma de interpelación y ciudadanización, entendida como el trabajo voluntario creativo para la expresión individual y el 92 ejercicio del derecho a ser escuchados, pues la autorepresentación deriva en empoderamiento, que es el revés de las relaciones de poder (Low, Brushwood, Salvio y Palacios, 2012).

Ahora bien, la implementación del método tiene varias etapas. Según el modelo planteado por el StoryCenter (Lambert, 2013), la primera fase es la creación de un círculo de historias, en el que las personas se 
reúnen para reflexionar sobre aquello que quieren contar y la forma de hacerlo. Para ello, reciben el acompañamiento de un facilitador, quien aporta la tecnología y la asistencia técnica necesaria para producir las narrativas digitales. Por lo general, se utilizan aplicaciones sencillas disponibles en cualquier computadora o teléfono celular (Smartphone) como editores de audio, video e imágenes. En la segunda fase del proceso cada participante elabora un guión escrito con el apoyo del facilitador, y un guión gráfico (Storyboard) estructurado con fotografías personales o representativas. Posteriormente, el narrador graba su voz, elige una banda sonora de música o sonido ambiental, y se hace el ensamblaje audiovisual en un programa de edición. En la última fase, se exhiben los productos ante la comunidad y se publican en un sitio de internet creado exprofeso, o en una plataforma de acceso abierto como YouTube, con el consentimiento verbal y escrito de cada participante, o, si lo prefieren, los videos pueden conservarse para uso personal o comunitario. En una etapa posterior se puede considerar la presentación de las narrativas digitales como evidencia ante los encargados del diseño de políticas públicas, a fin de lograr determinados objetivos que beneficien a la comunidad.

Los temas que abordan las narrativas digitales son múltiples y variados, según los intereses de los participantes. Sin embargo, los temas naturales de la narrativa digital son los relacionados con conflictos de raza, género, clase, orientación sexual, o eventos traumáticos e injusticias que silencian y oprimen a individuos $\mathrm{y}$ comunidades. Así, el método ha sido utilizado en campos diversos como el activismo ambiental, la salud pública, el desarrollo comunitario, los derechos humanos, la educación, ${ }^{4}$ la prevención de la violencia, la capacitación tecnológica, el periodismo ciudadano, la memoria colectiva e histórica, la comunicación organizacional, la 
comunicación intergeneracional o entre las diásporas, entre otras aplicaciones. ${ }^{5}$

\section{El contenido del archivo público "Humanizando la Deportación"}

Si bien el archivo público de narrativas digitales "Humanizando la Deportación" no pretende la representatividad estadística de la población afectada por la deportación, sino su significatividad, para mostrar la complejidad de este fenómeno en términos de las consecuencias humanas que produce, en los párrafos siguientes se describirá grosso modo el perfil de los narradores y las temáticas abordadas, a fin de ofrecer un panorama sobre el contenido del archivo. Es importante señalar que esta información se desprende de las propias narrativas digitales.

En las 45 narrativas publicadas hasta el mes de septiembre de 20I7, participaron 29 hombres y 8 mujeres, cuyas edades fluctúan entre los 20 y 70 años de edad, aunque gran parte de ellos son mayores de 40 años. Del total de participantes, 33 tenían familia en Estados Unidos, ya fueran hijos, cónyuge u otros, por lo que habían experimentado la separación familiar, especialmente en nueve casos que tenían hijos pequeños que se quedaron en aquel país. Alrededor de diez participantes vivían en albergues temporales en la ciudad de Tijuana; un promedio de 25 , en casas de renta o de familiares, y tres no especificaron esta información.

Las causas de expulsión de Estados Unidos que mencionaron los participantes fueron muy diversas: redadas en el área de trabajo; detenciones al cruzar la frontera; detenciones al tramitar la residencia legal o en un retén de la policía; por consumo de alcohol o drogas; por posesión y venta de drogas; manejar con aliento 
alcohólico (DUI, Driving Under the Influence) $\mathrm{u}$ otras infracciones de tránsito; porque alguien los denunció ante las autoridades migratorias, o bien, fueron removidos de las cárceles donde cumplían una condena. Así mismo, varios participantes expresaron haber sido manipulados para firmar una "salida voluntaria" de aquel país.

Como es sabido, las formas en que se produce el retorno forzado o la expulsión de Estados Unidos son la devolución (returned), que son los migrantes aprehendidos en la frontera y devueltos a territorio mexicano, sin consecuencias legales graves para el inmigrante, y la remoción (removal), que es la deportación por orden judicial, con consecuencias legales graves para el inmigrante, como el recibir una sentencia en prisión o la prohibición temporal o definitiva para reingresar a territorio norteamericano (Alonso, 2012 y 2015). Sin embargo, también existe la modalidad de la "autodeportación" o "salida voluntaria", que es cuando las personas son coaccionadas para firmar una orden de remoción (Stipulated Removal Order), sin especificar que con ello renuncian a su derecho de audiencia ante un juez y sin proporcionarles una copia del documento para emprender una apelación (Alarcón y Becerra, 2012).

Los trabajos u oficios que desarrollaban las personas eran en el área de servicios, de la construcción u otras, o se encontraban estudiando en el momento de su detención. En especial, tres participantes eran veteranos de guerra o de la Marina de Estados Unidos; dos eran exguerrilleros centroamericanos; dos eran beneficiarios del programa DACA (Acción Diferida para Llegados en la Infancia, por sus siglas en inglés), y uno, animador de televisión.

Por otro lado, las temáticas que aborda el archivo son muy heterogéneas, pero se pueden identificar algunas líneas generales, 
como se describirá a continuación (en cada caso se refieren las narrativas digitales que pueden consultarse):

El endurecimiento de las leyes y políticas migratorias

Las narrativas digitales evidencian que las medidas implementadas por Estados Unidos para expulsar a personas en situación migratoria irregular son cada vez más arbitrarias e inhumanas, pues se castiga con la deportación cualquier falta cometida, que puede ir desde una infracción de tránsito hasta un delito grave, sin considerar la especificidad de cada caso (Gómez, 2017; Barajas, 2017a y b; García, 20I7; De León, 20I7; Martín, 20I7). El castigo se acentúa cuando es aplicado a mujeres que tienen hijos menores de edad y para quienes no se considera ninguna excepción de carácter humanitario (Sánchez de Paulsen, 20I7; Galván, 20I7; Estrada, 20I7). Tampoco se indaga si han sido buenos ciudadanos y han pagado impuestos, o incluso, que hayan servido a las fuerzas armadas de aquel país (Madrid, 20I7; De León, 20I7; Murillo, 20I7). En el caso de los veteranos de guerra o de la Marina de Estados Unidos, llama la atención que tuviesen documentos de residencia legal, pero, por una falta administrativa, les retiraran estos derechos con el argumento de que, al no haber intervenido en alguna acción bélica, sino solamente en patrullajes militares, no tenían derecho a la ciudadanía, aun cuando defendieron la bandera de aquella nación.

Los criterios aleatorios para detener a inmigrantes o residentes de larga estadía 
En el empeño por expulsar personas se aplican criterios aleatorios mediante redadas en las áreas laborales y en retenes carreteros, o se ejecutan procedimientos expeditos si una persona denuncia a un inmigrante ante las autoridades migratorias (Sánchez González, 20I7; Gonsaga, 20I7; Jesús, 20I7; Villegas, 20I7; Muñoz, 20I7; Jorge, 20I7). Lo anterior, aunado a las devoluciones que se derivan de cruzar la frontera ilegalmente; las deportaciones al salir de prisión, y la coacción para que las personas firmen una salida voluntaria, como ya se mencionó (Bravo, 20I7; Valle, 20I7; Davis, 20I7b; Ortega, 20I7). Los castigos más severos que refieren las personas son la pena de io años para impedir el reingreso al país, o de 99 años por cruzar ilegalmente la frontera, sin importar que hayan dejado a sus hijos en Estados Unidos (Gómez, 2017; Anónimo, 2017).

\section{El drama del desarraigo y la precarización de la población retornada}

Las narrativas digitales expresan el drama del desarraigo que sufren las personas que residieron por más de 20 años en Estados Unidos, y que, al ser retornadas a nuestro país experimentan un choque cultural ante la falta de redes familiares o sociales que los ayuden a reintegrarse positivamente. Además, al haber perdido su empleo y los bienes materiales que tenían en aquel país, y al no encontrar trabajo en México, agotan sus recursos económicos y muchas veces terminan en situación de calle, donde sus condiciones se agravan hasta un grado de extrema precariedad (López, 20I7; Gómez, 20I7; Valle, 20I7; Barajas, 20I7a y b; Davis, 20I7b; Estrada, 20I7). El drama existencial es mayor si fueron llevados a Estados Unidos desde la infancia y, por lo tanto, no tienen lazos en México, salvo las reminiscencias y la herencia cultural de sus padres. En muchos casos, no dominan el idioma español, lo cual también complejiza su reintegración (Jáuregui, 20I7; Madrid, 20I7; Arturo, 2017; Méndez, 2017). Un caso especial es el de las personas de la tercera edad, pues su propia 
condición los limita para encontrar una oportunidad de trabajo y los sitúa en una posición de mayor vulnerabilidad (López, 20I7; De León, 20I7; Salas, 20I7; López Benavides, 20I7; Gonsaga, 20I7).

\section{Las violaciones a los derechos humanos}

El tema de los centros de detención para inmigrantes también revela una de las consecuencias humanas de la deportación, que es la violación sistemática de los derechos humanos y la manera en que estos espacios quebrantan la salud física, mental y emocional de las personas antes de ser expulsadas. Cuando llegan a nuestro país, se enfrentan a nuevas adversidades y se dificulta aún más su reinserción social y laboral.

Por otra parte, la criminalización de los inmigrantes en Estados Unidos se reproduce en México - específicamente en Tijuana- una vez que la policía los identifica como personas retornadas, sobre todo quienes se encuentran en situación de calle, sin que medie sustento jurídico para su detención y traslado a la cárcel municipal o a otros centros penitenciarios.

Tanto la policía de Estados Unidos y los agentes migratorios, como la policía local en México - municipal, estatal o federal-, desempeñan un papel de control, represión, acoso y persecución de los migrantes. Las interacciones que refieren las personas con los diversos agentes

98 son violentas, cargadas de racismo y discriminación (Sánchez González, 20I7; López, 20I7; Villegas, 2017; Jáuregui, 20I7; Madrid, 20I7; Gonsaga, 20I7; Tomás, 20I7; Manzo, 20I7; Davis, 20I7c; García, 20I7). A este respecto, destaca la experiencia violenta que vivieron casi mil personas retornadas que residían de manera irregular en El Bordo de la canalización del río Tijuana, cuando la policía municipal 
los trasladó contra su voluntad a centros de rehabilitación y a otros espacios desconocidos en los que debieron permanecer por tiempo indefinido, a pesar de que no todas las personas consumían drogas. Así mismo, otros narradores relatan sus experiencias cuando se encontraban en El Bordo, a falta de un lugar donde vivir (Davis, 20I7a y c; Tomás, 20I7; Manzo, 20I7; García, 20I7; Mendívil, 20I7a, b y c).

Los riesgos y peligros del cruce clandestino de la frontera

Los peligros que enfrentan las personas al cruzar la frontera de manera clandestina se manifiestan también en las narrativas digitales cuando evocan agresiones del crimen organizado, que se ha posicionado de las rutas de los migrantes para cobrarles derecho de paso, extorsionarlos, secuestrarlos o forzarlos a involucrarse en el trasiego de drogas (Manzo, 20I7; Esteban, 20I7). O los problemas de salud derivados de cruzar el río y los pantanos de la frontera, como relata Morales (20I7), una mujer a quien le negaron la atención médica una vez que fue llevada al centro de detención para inmigrantes.

La importancia de las organizaciones civiles y religiosas en Tijuana

El conjunto de narrativas digitales refleja el papel protagónico que han tenido las organizaciones civiles y religiosas, los albergues y grupos de activistas de Tijuana en la intervención humanitaria para paliar los efectos del retorno forzado, ante la falta de capacidad y compromiso de las instancias gubernamentales encargadas de su atención (Mendívil, 20I7c; Martín, 20I7; Davis, 20I7a; Salas, 20I7; García, 20I7). Al carecer de redes sociales y familiares en México, las 
personas encuentran en la sociedad civil organizada o en las entidades religiosas un nuevo capital social que les permite enfrentar sus necesidades más apremiantes como alimento, albergue y vestido.

La educación y la reinserción laboral

Entre los problemas que enfrentan las personas retornadas se encuentra la falta de apoyo en México para revalidar los estudios formales que desarrollaron en Estados Unidos, a fin de reinsertarse laboralmente en nuestro país, como muestra el caso de Martín (20I7), quien a pesar de tener documentos que lo certificaban como técnico, no conseguía empleo en México porque eran papeles de instituciones estadounidenses. En otros testimonios, se trataba de universitarios cuyos estudios fueron truncados por la deportación (Jáuregui, 20I7; Oláguez, 20I7; Bravo, 20I7). Incluso, varios jóvenes estaban protegidos por el programa DACA, pero un error en su vida propició su expulsión (Ángel, 20I7; Arturo, 20I7).

\section{Las deportaciones múltiples}

Otra temática compleja que se muestra en el archivo de narrativas digitales es el de las deportaciones múltiples que sufren las personas en su intento por reingresar a Estados Unidos de manera irregular. Este empeño es considerado por las autoridades migratorias como una reincidencia delictiva que se castiga con cárcel, cuando lo que quieren las personas es regresar con su familia (Sánchez González, 2017; Tomás, 2017; Gonsaga, 2017). 


\section{El arte y la deportación}

Tres casos excepcionales son las narrativas digitales de Tomás (20I7), Galván (20I7) y Méndez (20I7), pues a través del arte comunican sus experiencias con la deportación. Tomás (2017) comparte dos poemas sobre la forma de vida que ha llevado en México a raíz de su expulsión de Estados Unidos, y considera que se encuentra en condiciones de refugiado por la marginación de la que ha sido objeto. Así mismo, dedica otro de sus poemas a las personas que consumían heroína en El Bordo. Por su parte, Galván (2017) lee el cuento infantil "Mamá leona contra el muro", que escribió para sus hijas pequeñas, de las que fue separada por la deportación. En su historia hace una fábula de una leona que se ha enfrentado sin éxito a otras fieras y a una gran jaula en la frontera, pero que se sabe capaz de superar la adversidad para regresar algún día con sus hijas. Y Méndez (20I7) narra la trayectoria migratoria de su familia desde que su padre fue bracero en los años sesenta, y expresa sus opiniones políticas en torno a la criminalización de los inmigrantes y el consumo de drogas, lo cual considera una guerra contra las minorías. Las imágenes con las que cuenta su historia son tatuajes y bocetos a lápiz que la misma narradora diseñó, ya que es tatuadora de oficio.

\section{La pandemia de las adicciones}

El tema de las adicciones está presente en los testimonios que reúne el archivo de narrativas digitales, tanto en experiencias de consumo de alcohol (López, 20I7; Madrid, 20I7; Tejada, 20I7), como de consumo y venta de drogas, que propiciaron la expulsión de las personas (Jáuregui, 20I7; Manzo, 20I7; Méndez, 20I7; Murillo, 20I7; López Benavides, 20I7). Debe recordarse que desde los años ochenta, con el presidente Ronald Reagan, se emprendió el combate contra las 
drogas y el crimen organizado, pero fue con la Ley Anti-drogas de I998 cuando se extendió la penalización de estos hechos con la deportación, para el caso de las personas en situación migratoria irregular.

\section{La cultura de la migración}

Las narrativas digitales de Esteban (20I7) e Ismael (20I7) ofrecen un interesante contraste sobre la migración y la deportación, pues ambos narradores hacen una introspección para reflexionar sobre ello desde sus creencias, actitudes y sentimientos: mientras Ismael es un joven que apenas está en sus primeros intentos de cruzar la frontera y está lleno de sueños y esperanzas por alcanzar una vida mejor en Estados Unidos, Esteban es un hombre maduro que ya tuvo la experiencia y ha sido deportado, y ahora se encuentra en una nueva etapa, abriéndose camino en México. Ambas narrativas expresan un sistema de creencias desde el autodescubrimiento, que dibuja los trazos esenciales de la cultura migratoria.

\section{El archivo "Humanizando la Deportación" como fuente histórica}

La narrativa digital como género testimonial y como método que abrevó del paradigma sociocrítico, se vincula transversalmente a los paradigmas historiográficos que se desarrollaron a partir de los años setenta, como la historia cultural, la historia social, la historia desde abajo y la historia oral, en el sentido de que estas corrientes revalorizaron el papel de la cultura y de las clases populares como agentes históricos, con lo cual la clase dominante dejó de ser la única protagonista de la historia. 
En la ciencia histórica se dio un desplazamiento de las fuentes tradicionales, que eran los documentos históricos, para ampliar el número de fuentes, métodos y disciplinas convergentes (Santana, 2005). Al mismo tiempo, fue retomada la teoría crítica para rescatar la subjetividad humana que había sido negada o marginada de la historiografía. Así, adquirieron importancia la vida cotidiana, las creencias, opiniones, sentimientos y actitudes de la gente común en relación a sus experiencias de cambio social.

Esta revitalización de los enfoques humanistas buscaba, además de reconocer al actor social tanto individual como colectivo, romper el silencio sistemático que se les había impuesto a las minorías o a cualquier grupo marginado por criterios de raza, etnia, religión, género, clase social u orientación sexual, a fin de recuperar su voz y devolverles su legitimidad (Pujadas, 2000).

Así, el archivo de narrativas digitales "Humanizando la Deportación" constituye una fuente histórica significativa, no solo por su cualidad de fuente fija, es decir, como archivo público, sino porque permite construir conocimiento sobre los modos de pensar, las creencias, valores, aspectos identitarios, situación política y cultural de personas y grupos en un contexto histórico social concreto (Pujadas, 2000; Sanz, 2005).

Como fuente de historia oral, por ejemplo, aporta una diversidad testimonial respecto a procesos históricos y formas de relación social, pues cada historia, en su unicidad, revela conflictos latentes en las estructuras sociales (Burke, 1996). Si bien las fuentes orales no aportan necesariamente precisión formal en torno a fechas y datos, poseen otras cualidades que arrojan luz sobre los hechos históricos y las formas de pensar, sentir y experimentar tales hechos. Como señala Prins (1996), en la memoria humana se mantienen con viveza 
las huellas culturales, por lo que es capaz de contener y transmitir gran cantidad de conocimiento.

Desde otra perspectiva, el archivo puede abordarse como memoria colectiva, dado que se trata de un conjunto de testimonios de personas que tienen un discurso compartido en torno a un hecho vivido que trasciende al tiempo y al espacio (Pujadas, 200o). Esto es, que reúne recuerdos sobre acontecimientos públicos que aportan los miembros de un grupo o sociedad (Burke, I999), que en este caso es la comunidad migrante. Aunque cada historia humana es única y está colmada de eventos y circunstancias inaprensibles en su totalidad, incluso para el propio sujeto, el propósito es identificar el sentido de dicho discurso en su doble faceta de individualidad y como sujeto histórico, citando a Sanz (2005), ya que en la memoria individual se vinculan tanto las experiencias vividas por el sujeto como la dimensión social, el espacio y el tiempo de sus coetáneos.

\section{Reflexiones finales}

La riqueza temática del archivo público de narrativas digitales "Humanizando la Deportación" constituye un valioso recurso como fuente de información para múltiples aproximaciones epistemológicas, en especial como fuente histórica, porque rescata y preserva la voz de las personas afectadas por la deportación, pero desde la perspectiva de la autorepresentación, que es su principal aportación al campo de los estudios migratorios.

La especificidad de la metodología de la narrativa digital, cuyo fundamento es la autenticidad, es decir, la autoría de los narradores comunitarios, la distingue de otros métodos porque son los participantes quienes tienen el control del proceso; no para responder una serie de preguntas de los investigadores, sino para asumir sus experiencias y expresar libremente la historia que 
consideran más apremiante para comunicar al mundo. Al final, son los propios participantes quienes se benefician de esta intervención, pues se asumen como autores de una obra creativa que se vuelve pública, cuyo contenido permite superar la visión estereotipada que se tiene en torno a la población inmigrante, particularmente de aquellos que han sido retornados de Estados Unidos y que viven en condiciones precarias en nuestro país. De esta manera, el archivo contribuye a la humanización de estos procesos.

Hasta ahora, este proyecto es el único en su tipo que ha efectuado una intervención con esta población desde la perspectiva sociocrítica, a diferencia de otras fuentes mediáticas que abordan la temática a través de documentales, entrevistas, testimonios o reportajes, que si bien aportan información sustancial sobre el fenómeno, no tienen como propósito generar un cambio en los participantes. Toca ahora el turno a los investigadores sociales e historiadores de recuperar el archivo y reinterpretarlo desde su propia visión, a fin de generar conocimiento y seguir fortaleciendo el sentido de comunidad mediante la implementación de diversas estrategias de visibilización de los grandes problemas sociales que vive nuestro país en el contexto contemporáneo. Finalmente el archivo de narrativas digitales no solo muestra las consecuencias humanas de la deportación, sino que a través de ellas es posible leer el devenir de la migración a nivel latinoamericano.

\section{Referencias}

Alarcón, R. y W. Becerra (20I2). “¿Criminales o víctimas? La deportación de migrantes mexicanos de Estados Unidos a Tijuana, Baja California”. Norteamérica, vol. 7, núm. I, enerojunio, pp. 125-248. 
Alonso Meneses, G. (20I5). El desierto de los sueños rotos. Detenciones y muertes de migrantes en la frontera México-Estados Unidos (199320I3). I ${ }^{\mathrm{a}}$ edición en formato digital. México, El Colegio de la Frontera Norte, A.C.

Alonso Meneses, G. (2012). "Recesión económica, reflujos migratorios y violencia antiinmigrante entre México y Estados Unidos". Norteamérica, vol. 7, núm. 2, julio-diciembre, pp. 22I-25I.

Ángel, A. (20I7). "Solamente otro negocio", narrativa digital, Humanizando la Deportación, Universidad de California, Davis, en

<http://humanizandoladeportacion.ucdavis.edu/es/2017/o8/o8/s olo-otro-negocio/>.

Anónimo (20I7). "Futuro secuestrado", narrativa digital, Humanizando la Deportación, Universidad de California, Davis, en

$<$ http://humanizandoladeportacion.ucdavis.edu/es/20I7/I2/20/an onimo/>.

Arcudia García, I. y F. A. Pérez Piñón (20I4). "Historia oral e historia inmediata. La recuperación del sujeto educativo mediante la historiografía crítica”. Noesis, vol. 23, núm. 46, julio-diciembre, pp. 308-33I.

Arturo (2017). "Mi pasado y mi presente", narrativa digital, Humanizando la Deportación, Universidad de California, Davis, en <http://humanizandoladeportacion.ucdavis.edu/es/20I7/o8/o9/ mi-pasado-y-mi-presente/>.

Barajas Varela, H. (20I7a). “El sueño americano? (Parte I)”, narrativa digital, Humanizando la Deportación, Universidad de California, Davis, en $<$ http://humanizandoladeportacion.ucdavis.edu/es/20I7/o8/2I/el -sueno-americano-parte-i/>. 
Barajas Varela, H. (20I7b). “¿El sueño americano? (Parte II)”, narrativa digital, Humanizando la Deportación, Universidad de California, Davis, en $<$ http:/humanizandoladeportacion.ucdavis.edu/es/20I7/o8/2I/el -sueno-americano-parte-ii/>.

Bravo, R. (20I7). "Nacional: Título 8IIoI (22). Por lo tanto, un americano. Conoce quién eres", narrativa digital, Humanizando la Deportación, Universidad de California, Davis, en $<$ http://humanizandoladeportacion.ucdavis.edu/es/20I7/o8/2I/n acional-titulo-8-IIOI-22-b-por-lo-tanto-un-americano-se-quieneres/>.

Burgess, J. (2006). "Hearing Ordinary Voices: Cultural Studies, Vernacular Creativity and Digital Storytelling”. Continuum, 20(2), pp. 2OI-2I4.

Burke, P. (1999). Formas de historia cultural. Belén Urrutia (trad.). Madrid, Alianza Editorial.

Burke, P. (I996). "Historia de los acontecimientos y renacimiento de la narración", en Formas de hacer historia, Peter Burke (ed.). Barcelona, Alianza editorial.

Davis Pozo, I. (20I7a). "Historia del Apá", narrativa digital, Humanizando la Deportación, Universidad de California, Davis, en

$<$ http://humanizandoladeportacion.ucdavis.edu/es/20I7/o7/29/hi storia-del-apa/>.

Davis Pozo, I. (20I7b). "Regresar como Dios manda", narrativa digital, Humanizando la Deportación, Universidad de California, Davis, en

$<$ http://humanizandoladeportacion.ucdavis.edu/es/20I7/o7/29/re gresar-como-dios-manda/>.

Davis Pozo, I. (20I7c). "Sobrevivir al Bordo (Parte I)", narrativa digital, Humanizando la Deportación, Universidad de California, Davis, 
en

<http://humanizandoladeportacion.ucdavis.edu/es/20I7/o8/o3/s obrevivir-al-bordo-parte-i/>.

De León, A. (20I7). "La vida de un veterano deportado a los 73 años de edad", narrativa digital, Humanizando la Deportación, Universidad de California, Davis, en <http://humanizandoladeportacion.ucdavis.edu/es/20I7/o7/26/la -vida-de-un-veterano-deportado-a-las-73-anos-de-edad/>.

Díaz-Kommonen, L. (2007). "Narrativa digital para sistemas interactivos relacionados con la herencia cultural". Cuadernos de Literatura, vol. I2, núm. 23, julio-diciembre, pp. I53-I64.

Esteban (20I7). “Aquí también hay prosperidad”, narrativa digital, Humanizando la Deportación, Universidad de California, Davis, en

<http://humanizandoladeportacion.ucdavis.edu/es/20I7/o7/26/a qui-tambien-hay-prosperidad-esteban/>.

Estrada, E. (20I7). "Regresar con libertad", narrativa digital, Humanizando la Deportación, Universidad de California, Davis, en

<http://humanizandoladeportacion.ucdavis.edu/es/20I7/o8/o9/s uenos-falsos/>.

Galván Godoy, M. (20I7). “Mamá leona contra el muro”, narrativa digital, Humanizando la Deportación, Universidad de California, Davis, <http://humanizandoladeportacion.ucdavis.edu/es/20I7/o7/3I/m ama-leona-contra-el-muro/>.

García García, L. (20I7). "Levantarse con fuerza para ayudar", narrativa digital, Humanizando la Deportación, Universidad de California, Davis, en $<$ http:/humanizandoladeportacion.ucdavis.edu/es/20I7/o8/15/le vantarse-con-fuerza-para-ayudar/>. 
Gómez Zavala, J. (20I7). "El Boxeador", narrativa digital, Humanizando la Deportación, Universidad de California, Davis, en

$<$ http://humanizandoladeportacion.ucdavis.edu/es/20I7/o7/26/el -boxeador/>.

Gonsaga Hernández, L. (20I7). "La ilusión y los obstáculos”, narrativa digital, Humanizando la Deportación, Universidad de California, Davis, en $<$ http://humanizandoladeportacion.ucdavis.edu/es/20I7/Io/oI/lailusion-y-los-obstaculos/>.

Hermann Acosta, A. (2015). "Narrativas digitales como didácticas y estrategias de aprendizaje en los procesos de asimilación y retención del conocimiento". Sophia, núm. 19, pp. 253-269.

Ismael (20I7). "Y ese es Ismael", narrativa digital, Humanizando la Deportación, Universidad de California, Davis, en $<\mathrm{http}$ //humanizandoladeportacion.ucdavis.edu/es/20I7/o7/20/yese-es-ismael/>.

Jáuregui Mariz, J. (20I7). "Primero te americanizan, luego te expulsan", narrativa digital, Humanizando la Deportación, Universidad de California, Davis, en $<$ http://humanizandoladeportacion.ucdavis.edu/es/20I7/o7/19/pr imero-te-americanizan-luego-te-expulsan/>.

Jesús (20I7). "Mi sueño no termina ahí", narrativa digital, Humanizando la Deportación, Universidad de California, Davis, en

$<$ http://humanizandoladeportacion.ucdavis.edu/es/20I7/o8/15/m i-sueno-no-termina-ahi/>.

Jorge (2017). "Hecho un criminal en América", narrativa digital, Humanizando la Deportación, Universidad de California, Davis, en 
$<$ http://humanizandoladeportacion.ucdavis.edu/es/20I7/08/05/h echo-un-criminal-en-america-2/>.

Lambert, J. (2013). Digital Storytelling. Capturing Lives, Creating Community. Nueva York y Londres, Routledge, $4^{\mathrm{a}} \mathrm{ed}$.

Lizarazo, T., Oceguera, E., Tenorio, D., Pardo Pedraza, D. y McKee Irwin R. (2017). "Ethics, Collaboration and Knowledge Production: Digital Storytelling with Sexually Diverse Farmworkers in California”. Lateral 6.I, primavera, pp. I-2I.

López, R. (20I7). "Aprovecha la oportunidad", narrativa digital, Humanizando la Deportación, Universidad de California, Davis, en

<http://humanizandoladeportacion.ucdavis.edu/es/20I7/05/I8/ap rovecha-la-oportunidad/>.

López Benavides, J. A. (20I7). "Un sueño frustrado: la historia de un salvadoreño", narrativa digital, Humanizando la Deportación, Universidad de California, Davis, en <http://humanizandoladeportacion.ucdavis.edu/es/20I7/o8/I6/u n-sueno-frustrado/>.

Low, B., C. Brushwood Rose, P. M. Salvio y L. Palacios (20I2). “(Re) framing the Scholarship on Participatory Video: From Celebration to Critical Engagement", en Handbook of Participatory Video, D-J. Milne, Claudia Mitchell y Naydene De Lange (eds.). Reino Unido, AltaMira Press.

Madrid, J. (2017). “¿Residencia permanente? La historia de un veterano de la Infantería Marina de los Estados Unidos”, narrativa digital, Humanizando la Deportación, Universidad de California, Davis, en <http://humanizandoladeportacion.ucdavis.edu/es/20I7/o7/26/re sidencia-permanente-la-historia-de-un-veterano-de-lainfanteria-marina-de-los-estados-unidos/>. 
Mak, M. (2012). "Visual postproduction in participatory video-making processes", en Handbook of Participatory Video, D-J. Milne, Claudia Mitchell y Naydene De Lange (eds.). Reino Unido, AltaMira Press.

Manzo, R. (20I7). “I8 años para abandonar El Bordo”, narrativa digital, Humanizando la Deportación, Universidad de California, Davis, en

$<$ http://humanizandoladeportacion.ucdavis.edu/es/20I7/o7/20/18 -anos-para-abandonar-el-bordo/>.

Martín (20I7). "Vas para tu país”, narrativa digital, Humanizando la Deportación, Universidad de California, Davis, en $<\mathrm{http}$ //humanizandoladeportacion.ucdavis.edu/es/2017/07/29/v as-para-tu-pais/>.

McKee Irwin, R. (20I6). "Taller de narrativa digital como método de investigación: colaboración comunitaria, voz vernácula”, IO, II y I4 de noviembre de 20I6, El Colegio de la Frontera Norte, Tijuana, disponible en: <https://www.youtube.com/watch?v=iDOtw7ImRQE\&t=204Is >.

Méndez, J. (20I7). “Alas pa'volar”, narrativa digital, Humanizando la Deportación, Universidad de California, Davis, en <http://humanizandoladeportacion.ucdavis.edu/es/20I7/o8/05/al as-pa-volar/>.

Mendívil, G. R. (20I7a). "Gracias a los deportados, otra oportunidad. Parte I: Niño callejero", narrativa digital, Humanizando la Deportación, Universidad de California, Davis, en $<$ http://humanizandoladeportacion.ucdavis.edu/es/20I7/Io/26/gr acias-a-los-deportados-otra-oportunidad/>.

Mendívil, G. R. (20I7b). "Gracias a los deportados, otra oportunidad. Parte 2: Adicción", narrativa digital, Humanizando la Deportación, Universidad de California, Davis, en 
<http://humanizandoladeportacion.ucdavis.edu/es/20I7/II/I2/gra cias-a-los-deportados-otra-oportunidad-parte-2-adiccion/>.

Mendívil, G. R. (20I7c). "Gracias a los deportados, otra oportunidad. Parte 3: Superación", narrativa digital, Humanizando la Deportación, Universidad de California, Davis, en <http://humanizandoladeportacion.ucdavis.edu/es/20I7/II/I4/gr acias-a-los-deportados-otra-oportunidad-parte-3-superacion/>.

Morales Guzmán, E. (20I7). “Guerrera incansable II”, narrativa digital, Humanizando la Deportación, Universidad de California, Davis, en

$<$ http://humanizandoladeportacion.ucdavis.edu/es/2017/o7/26/g uerrera-incansable-ii/>.

Muñoz, S. (20I7a). "Entre el tiempo, mis hijos y la frontera (Parte I)", narrativa digital, Humanizando la Deportación, Universidad de California, Davis, en $<$ http://humanizandoladeportacion.ucdavis.edu/es/2017/07/30/e ntre-el-tiempo-mis-hijos-y-la-frontera-parte-I/>.

Muñoz, S. (20I7b). "Entre el tiempo, mis hijos y la frontera (Parte 2)", narrativa digital, Humanizando la Deportación, Universidad de California, Davis, en $<$ http://humanizandoladeportacion.ucdavis.edu/es/20I7/o7/30/e ntre-el-tiempo-mis-hijos-y-la-frontera-parte-2/>.

Murillo, A. (20I7). "Soldados americanos en el exilio", narrativa digital, Humanizando la Deportación, Universidad de California, Davis, en $<$ http://humanizandoladeportacion.ucdavis.edu/es/20I7/o8/15/so ldados-americanos-en-exilio/>.

Oláguez, J. (20I7). "Familia encima de todo", narrativa digital, Humanizando la Deportación, Universidad de California, Davis, en 
$<$ http://humanizandoladeportacion.ucdavis.edu/es/20I7/o8/o5/fa milia-encima-de-todo/>.

Ortega, R. y Z. (20I7). "Asumiendo el rol", narrativa digital, Humanizando la Deportación, Universidad de California, Davis, en

$<$ http://humanizandoladeportacion.ucdavis.edu/es/20I7/I2/o4/st eppin-in-2/>.

Pérez-Soltero, A., Aguayo-Salinas, M.E., Barceló-Valenzuela, M., Ochoa-Hernández, J.L. y Aja Leyva, H. (2013), "Narrativas digitales dentro de la memoria organizacional de una empresa de consultoría", en Avances de investigación en Ingeniería en el estado de Sonora, Germán Alonso Ruiz-Domínguez et al. (eds)., Universidad de Sonora, pp. 215-22I.

Prins, G. (1996). "Historia oral", en Formas de hacer historia, Peter Burke (ed.). Barcelona, Alianza editorial.

Pujadas, J. J. (2000). "El método biográfico y los géneros de la memoria”. Revista de Antropología Social, núm. 9, pp. I27-I58.

Rodríguez Ruiz, J. Al. (2009). “Asedio a las narrativas contemporáneas. Mapa de posibles investigaciones”. Cuadernos de Literatura, vol. I4, núm. 26, pp. I4-5I.

Salas Mesa, J. G. (20I7). "Para los deportados como yo", narrativa digital, Humanizando la Deportación, Universidad de California, Davis, en <http://humanizandoladeportacion.ucdavis.edu/es/20I7/o8/13/pa ra-los-deportados-como-yo/>.

Sánchez de Paulsen, E. (20I7). "El muro separa familias, pero jamás el sentimiento", narrativa digital, Humanizando la Deportación, Universidad de California, Davis, en $<$ http://humanizandoladeportacion.ucdavis.edu/es/2017/o7/13/elmuro-separa-a-familias-pero-jamas-sentimientos/>. 
Sánchez González, G. (20I7). "Crueles deportaciones”, narrativa digital, Humanizando la Deportación, Universidad de California, Davis, en $<$ http://humanizandoladeportacion.ucdavis.edu/es/2017/05/I8/cr ueles-deportaciones/>.

Santana Pérez, J. M. (2005). Paradigmas historiográficos contemporáneos. Venezuela, Fundación Buría.

Sanz Hernández, A. (2005). "El método biográfico en investigación social: potencialidades y limitaciones de las fuentes orales y los documentos personales". Asclepio, vol. 57, núm. I, pp. 99-II5.

SEGOB (20I5). "Eventos de repatriación de mexicanos desde Estados Unidos, según entidad federativa y punto de recepción, I99520I6”. Unidad de Política Migratoria, Secretaría de Gobernación.

Socas Guerra, V. y González González, C. S. (2013). “Usos educativos de la narrativa digital: una experiencia de M-Learning para la educación emocional". Teoría de la Educación. Educación y Cultura en la Sociedad de la Información, vol. I4, núm. 2, pp. 490-507.

Spurgeon, C. (2009). "Co-creative Media: Theorising Digital Storytelling as a platform for researching and developing participatory culture". Communication, Creativity and Global Citizenship, Brisbane, julio, pp. 274-286.

Tejada, J. E. (20I7). "El guerrero luchador de El Salvador", narrativa digital, Humanizando la Deportación, Universidad de California, Davis, en <http://humanizandoladeportacion.ucdavis.edu/es/2017/o8/II/elguerrero-luchador-de-el-salvador/>.

Tomás (20I7). "El Colgado", narrativa digital, Humanizando la Deportación, Universidad de California, Davis, en <http://humanizandoladeportacion.ucdavis.edu/es/2017/o7/13/elcolgado/ $>$. 
Valle Solís, P. (20I7). "El Chacal de Don Francisco", narrativa digital, Humanizando la Deportación, Universidad de California, Davis, en

$<$ http://humanizandoladeportacion.ucdavis.edu/es/2017/o7/26/el -chacal-de-don-francisco/>.

Villegas Galindo, J. M. (20I7). "Mi esposa, mis hijos, Dios me ayude", narrativa digital, Humanizando la Deportación, Universidad de California, Davis, en $<\mathrm{http}: /$ humanizandoladeportacion.ucdavis.edu/es/2017/07/13/mi -esposa-mis-hijos-dios-de-ayude/>.

Worcester, L. (2012). "Reframing Digital Storytelling as Co-creative". IDS Bulletin, vol. 43, núm. 5, septiembre.

${ }^{1}$ Robert McKee Irwin también es profesor del Departamento de Español y Portugués de la UC Davis, especialista en cultura mexicana y mexicoamericana, masculinidades y sexualidades, estudios fronterizos, estudios culturales y mediáticos, y narrativa digital. Es autor de Mexican Masculinities (2003), Bandits, Captives, Heroines and Saints: Cultural Icons of Mexico's Northwest Borderlands (2007), coeditor del Diccionario de estudios culturales latinoamericanos (20II), entre otros.

${ }^{2}$ http://humanizandoladeportacion.ucdavis.edu.

${ }^{3}$ Es importante agregar que las narrativas digitales están traducidas al inglés y al español, según el caso.

${ }^{4}$ En la educación las narrativas digitales suelen utilizarse como estrategias de aprendizaje; para reflexionar sobre la práctica docente, o para desarrollar la autoestima en los niños al posibilitar su autoexpresión y su capacidad narrativa, entre otras aplicaciones.

${ }^{5}$ Algunos ejemplos que pueden consultarse sobre las aplicaciones de la narrativa digital en campos diversos son Pérez-Soltero, Aguayo-Salinas, Barceló-Valenzuela, Ochoa-Hernández y Aja (2013), para la memoria organizacional de una empresa; Socas y González (2013), para la educación emocional en el contexto escolar; DíazKommonen (2007), para preservar la herencia cultural; Hermann (20I5), como estrategia de aprendizaje; Rodríguez (2009), sobre el papel de la narrativa digital en la literatura y en las ciencias sociales; Worcester (2012), con el programa de 
investigación sobre empoderamiento femenino en el sur de Asia, Pathways of Women's Empowerment Research Programme Consortium, y Lizarazo et al. (20I7), sobre la diversidad sexual en los campos agrícolas de Estados Unidos.

Este artículo se publica bajo una licencia de Creative Commons Reconocimiento-NoComercial 4.0 Internacional, y puede ser usados gratuitamente para fines no comerciales, dando los créditos a los autores y a la revista. 